\title{
Maternal mental health is associated with child undernutrition and illness in Bangladesh, Vietnam and Ethiopia
}

\author{
Phuong H Nguyen ${ }^{1, *}$, Kuntal K Saha ${ }^{2}$, Disha Ali ${ }^{3}$, Purnima Menon ${ }^{4}$, \\ Swetha Manohar ${ }^{5}$, Lan Tran Mai ${ }^{1}$, Rahul Rawat ${ }^{6}$ and Marie T Ruel ${ }^{6}$ \\ ${ }^{1}$ International Food Policy Research Institute (IFPRI), Alive \& Thrive, Room 203-204, E4B, Trung Tu Diplomatic \\ Compound, No. 6, Dang Van Ngu, Hanoi, Vietnam: ${ }^{2}$ IFPRI, Dhaka, Bangladesh: ${ }^{3}$ IFPRI, Addis Ababa, Ethiopia: \\ ${ }^{4}$ IFPRI, New Delhi, India: ${ }^{5} J o h n s$ Hopkins Bloomberg School of Public Health, Baltimore, MD, USA: 'IFPRI, \\ Washington, DC, USA
}

Submitted 21 July 2012: Final revision received 7 March 2013: Accepted 12 March 2013: First published online 3 May 2013

\begin{abstract}
Objective: We assessed associations of maternal common mental disorders (CMD) with undernutrition and two common illnesses in children aged $0-5$ years.

Design: Cross-sectional survey. Maternal CMD was measured using the WHO Self-Reporting Questionnaire-20. Child undernutrition was defined as stunting, underweight or wasting. Child illnesses included diarrhoea and acute respiratory infections (ARI). Multivariate logistic regression was used to test these associations adjusting for confounders at child, maternal and household levels.

Setting: Bangladesh, Vietnam and Ethiopia.

Subjects: Mothers with children aged 0-5 years from 4400 households in Bangladesh, 4029 households in Vietnam and 3000 households in Ethiopia.

Results: The prevalence of maternal CMD was high, ranging from $31 \%$ in Vietnam to $49 \%$ in Bangladesh. Child undernutrition was more prevalent in Bangladesh and Ethiopia than in Vietnam. Symptoms of ARI and diarrhoea were also prevalent. In multivariate analysis, maternal CMD was associated with child stunting in Bangladesh $(\mathrm{OR}=1 \cdot 21 ; 95 \% \mathrm{CI} 1 \cdot 03,1 \cdot 41)$ and with child underweight in Vietnam $(\mathrm{OR}=1 \cdot 27 ; 95 \% \mathrm{CI} 1 \cdot 01,1 \cdot 61)$; no association was found with wasting. Maternal CMD was strongly associated with diarrhoea and ARI in all three countries.

Conclusions: Maternal CMD, which affected nearly half of women in Bangladesh and one-third in Vietnam, was an important determinant of child stunting and underweight, respectively. No such association was found in Ethiopia, although CMD affected 39\% of women. Maternal CMD was strongly associated with childhood illnesses in all three countries. Interventions to support maternal mental health are important for women's own well-being and could make important contributions to improving child health and nutrition.
\end{abstract}

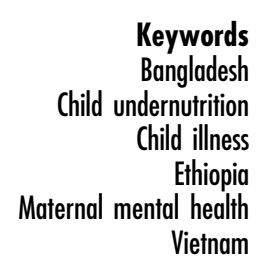

Maternal characteristics such as education, health and nutrition knowledge, empowerment, and physical and mental health are critical resources for child survival, growth and development ${ }^{(1)}$. The recent Lancet series on maternal and child undernutrition highlighted maternal depression as a significant risk factor for poor child growth and recommended interventions to address the problem through maternal and child health and nutrition programmes $^{(2)}$. Maternal behaviours and practices are important elements for translating resources for care, such as household food security and health-care resources, into child well-being ${ }^{(3,4)}$. Impaired mental health reduces a mother's ability to take adequate care of her child, which in turn can have negative effects on the child's growth and development ${ }^{(5-7)}$. Alternatively, the presence of a sick or poorly growing child could undermine a mother's well-being, thereby increasing her vulnerability to depressive symptoms due to the worry and stress of the additional effort required to take care of her child and the pressure of disappointment or even overt criticism expressed by family members or others ${ }^{(5)}$.

Poor maternal mental health has been shown to be associated with suboptimal breast-feeding and complementary feeding practices ${ }^{(8)}$, compromised parenting behaviours, reduced mother-child interactions and a higher prevalence of medical and emotional problems among children. Studies in India, Bangladesh and Pakistan demonstrated consistent associations between maternal common mental disorders (CMD) and child undernutrition $^{(9-11)}$. Results from cross-country studies indicated that in India and Vietnam, mothers with CMD had higher likelihood of having a stunted and underweight child, 
respectively, compared with mothers who did not suffer from CMD. In Peru and Ethiopia, however, these associations were not statistically significant ${ }^{(12)}$. Studies in Latin America and Africa also revealed mixed results. Maternal mental health was associated with child nutrition in Brazil ${ }^{(13,14)}$ and Malawi ${ }^{(15)}$, but not in South Africa ${ }^{(16)}$ and Ethiopia ${ }^{(17)}$. A recent meta-analysis of seventeen studies in eleven countries also provided evidence of the association between maternal depression and early childhood underweight and stunting in both cross-sectional and longitudinal studies ${ }^{(18)}$.

Few studies have examined the association between maternal mental health and child illnesses. In a cohort study in Pakistan, pre- and postnatal depression were found to increase the risk of having diarrhoea in infants ${ }^{(19,20)}$. Results from a case study in Nigeria also showed that infants of depressed mothers were more likely to have episodes of diarrhoea and other infectious illnesses ${ }^{(21)}$. In a recent study in Ethiopia, infants of mothers with persistent perinatal CMD symptoms were at more than double the risk of having diarrhoea. However, such associations were not observed between perinatal CMD symptoms and fever or acute respiratory infection (ARI) ${ }^{(22)}$

In the present study, we examined the associations of maternal CMD with child undernutrition and illnesses in Bangladesh, Vietnam and Ethiopia. We proposed that maternal CMD would be associated with greater levels of undernutrition and common illnesses in children. Use of the same measurement tools and analytical techniques was useful to demonstrate the associations of maternal CMD with child undernutrition and illnesses across the three countries.

\section{Materials and methods}

\section{Data source and study population}

We used data from the baseline household survey of Alive \& Thrive (A\&T), which is an initiative funded by the Bill \& Melinda Gates Foundation to reduce undernutrition and death caused by suboptimal infant and young child feeding (IYCF) practices in Bangladesh, Vietnam and Ethiopia over a period of six years (2008-2014). The Vietnam baseline survey covered 4029 households in forty communes in four provinces where the A\&T project is being implemented ${ }^{(23)}$. The Bangladesh baseline survey covered 4400 households in twenty selected upazilas (sub-districts) $^{(24)}$. The baseline survey in Ethiopia included a total of 3000 households from seventy-five enumeration $\operatorname{areas}^{(25)}$. All households with children aged $0-5$ years and their mothers were included in the survey. There were no exclusion criteria except for those who refused to participate (refusal was minimal across the three countries). All three surveys received ethical approval from the Institutional Review Board of the designated countries and from the International Food Policy Research Institute.

\section{Antbropometry}

The first outcome in the present study was child undernutrition - stunting, underweight and wasting. Weight and height/length measurements were taken by trained fieldworkers using recommended protocols ${ }^{(26)}$. Weight of children and mothers was measured using electronic scales accurate to $100 \mathrm{~g}$. Locally manufactured length/height boards, which were precise to $1 \mathrm{~mm}$, were used to measure the recumbent length of children aged 0-24 months and the standing height of children aged $\geq 24$ months and of mothers.

Children's weight and length/height measurements were used to derive $Z$-scores by comparing each child's anthropometric measurements with the WHO child growth standards for his/her age and gender ${ }^{(27)}$. Three indicators were calculated using child's weight and length/height: length/height-for-age $Z$-score (HAZ), weight-for-age $Z$-score (WAZ) and weight-for-length/height Z-score (WHZ). Stunting was defined as HAZ $<-2$, underweight as WAZ $<-2$ and wasting as WHZ $<-2^{(27)}$. Maternal weight and height were used to calculate BMI $\left(\mathrm{kg} / \mathrm{m}^{2}\right)$. Maternal undernutrition was defined as BMI $<18 \cdot 5 \mathrm{~kg} / \mathrm{m}^{2}$.

\section{Child illness}

The second outcome was child illness, which was measured through maternal recall of symptoms of diarrhoea and upper ARI in the two weeks prior to the survey. Diarrhoea was defined as three or more loose stools passed in a $24-\mathrm{h} \mathrm{period}^{(28)}$ and ARI was defined as the presence of cough/cold with fever and/or fast breathing ${ }^{(29)}$.

\section{Maternal common mental disorders}

Maternal CMD was measured using the WHOrecommended screening tool called the Self-Reporting Questionnaire-20 (SRQ-20) that includes twenty questions with a recall period of $30 \mathrm{~d}$ prior to the administration of the questionnaire $^{(30)}$. The SRQ-20 measures several symptoms of depression, including headache, poor appetite, sleep disturbance, depressed mood, unhappiness, helplessness and psychomotor retardation. Each question is given a score of 0 or 1 depending on the 'no' or 'yes' response, respectively. The scores are added to generate an overall SRQ-20 scale, where higher scores indicate higher levels of maternal CMD and vice versa. This tool has been found to be reliable, valid and adaptable for screening mental disorders in the developing world ${ }^{(30)}$ including Ethiopia ${ }^{(31)}$ and Vietnam ${ }^{(32)}$. We used a cut-off of 7 to classify women with low or high level of CMD, as suggested by several validation studies $^{(31,32)}$.

\section{Socio-economic status index}

The socio-economic status (SES) index was constructed using principal components analysis. Variables that were included in the SES index were ownership of house and land, housing quality (e.g. house construction materials), access to services (water, electricity, gas and sanitation 
services) and household assets (different types of durable goods, productive assets, animals and livestock) $)^{(33,34)}$. Factor scores derived from the first factor (which explained $47 \%, 33 \%$ and $39 \%$ of the variance for Bangladesh, Vietnam and Ethiopia, respectively) were then used to characterize the SES of each household. Households were categorized into SES quintiles based on their individual SES index score.

\section{Housebold food security}

Household food security was measured using the Household Food Insecurity Access Scale ${ }^{(35)}$ of the Food and Nutrition Technical Assistance Project/US Agency for International Development, which provides information on behaviour and perceptions related to household food insecurity - anxiety and uncertainty, insufficient quality of intake, insufficient food intake and its consequences. All the questions were asked for a reference period of $30 \mathrm{~d}$ preceding the survey. The households were categorized into four groups: food secure, mildly food insecure, moderately food insecure and severely food insecure ${ }^{(35)}$. These categories were then collapsed into two groups of households: food secure and food insecure (which included the mildly, moderately and severely food-insecure groups).

\section{Infant and young child feeding practices}

IYCF practice indicators were described using the WHO recommendation ${ }^{(36,37)}$. The six core IYCF indicators used in the present analysis were: (i) early initiation of breast-feeding (the proportion of children born in the last 24 months who were put to the breast within $1 \mathrm{~h}$ of birth); (ii) exclusive breast-feeding (the proportion of infants $0-5$ months of age who are fed exclusively with breast milk); (iii) minimum dietary diversity (the proportion of children 6-23 months of age who receive foods from four or more food groups); (iv) minimum meal frequency (the proportion of breast-fed and non-breast-fed children 6-23 months of age who receive solid/semi-solid food, the minimum number of times or more); (v) minimum acceptable diet (the proportion of children 6-23 months of age who receive at least the minimum dietary diversity and the minimum meal frequency, apart from breast milk); and (vi) consumption of Fe-rich foods (the proportion of children 6-23 months of age who received an Fe-rich food or a food that was fortified with Fe).

\section{Other variables}

We collected information on the child's birth weight. Low birth weight was defined as birth weight $<2500 \mathrm{~g}$ for Vietnam, and mother's perception that the child was very small or smaller than average for Bangladesh and Ethiopia. In addition, mother's and child's cleanliness was assessed based on a hygiene spot check ${ }^{(38)}$ of the general appearance of the face, hands, hair and body/clothes. Each question was given a score of 0 or 1 depending on the 'dirty' or 'clean' observation, respectively. The scores were added to generate an overall hygiene scale (range: $0-4$ ), where higher scores indicated higher levels of cleanliness. Women's education was measured as the years of schooling completed. As women's education levels varied across the three countries, different cut-offs were used for maternal education based on their suitability to the country's context. Whereas 'primary education' was used as the reference group in Vietnam, 'no schooling' was the reference group for Bangladesh and Ethiopia.

\section{Statistical analysis}

Descriptive analyses were used to report background characteristics of the study sample. Bivariate analysis was done to examine the association of maternal CMD with child undernutrition and child illness, and also with maternal and household characteristics, child feeding practices, hygiene and health-seeking behaviours, using the $t$ test for continuous variables and the $\chi^{2}$ test for categorical variables. Logistic regression models were used to examine the relationship of maternal CMD with child undernutrition and child illness, adjusting for several potential confounding factors at child (age, gender, low birth weight), maternal (age, height, BMI, education, mother as household head) and household levels (SES, food security). These models were also adjusted for mother's and child's cleanliness. The 'cluster' command in Stata was used to adjust for clustering effects at the sub-district level in Bangladesh, communes in Vietnam and region in Ethiopia. All statistical analyses were carried out using the statistical software package Stata version 11.

\section{Results}

\section{Sample characteristics}

Characteristics of the study population in Bangladesh, Vietnam and Ethiopia are presented in Table 1. Levels of undernutrition were high across the three countries. The prevalence of stunting was highest in Ethiopia (44\%) followed by Bangladesh ( $40 \%)$ and Vietnam (17\%). Rates of underweight and wasting were highest in Bangladesh followed by Ethiopia and Vietnam (39\%, 24\% and 13\% for underweight and $18 \%, 7 \%$ and $5 \%$ for wasting, respectively). A large number of children had symptoms of upper ARI during the previous two weeks (33\% in Bangladesh, $16 \%$ in Vietnam and $20 \%$ in Ethiopia). The prevalence of diarrhoea in Bangladesh (8\%) was lower than in the other two countries (9\% in Vietnam and 16\% in Ethiopia). Maternal CMD was high in all three countries, affecting nearly half of women in Bangladesh, 39\% of women in Ethiopia and $31 \%$ of women in Vietnam.

\section{Bivariate associations between maternal common mental disorders and child undernutrition and illness}

The prevalence of undernutrition and child illnesses by maternal CMD is shown in Fig. 1(a) and (b). Compared 
Table 1 Baseline characteristics of the study population in Bangladesh, Vietnam and Ethiopia; baseline data from Alive \& Thrive

\begin{tabular}{|c|c|c|c|c|c|c|}
\hline & \multicolumn{2}{|c|}{$\begin{array}{l}\text { Bangladesh } \\
\text { (n 4400) }\end{array}$} & \multicolumn{2}{|c|}{$\begin{array}{l}\text { Vietnam } \\
(n \text { 4010) }\end{array}$} & \multicolumn{2}{|c|}{$\begin{array}{l}\text { Ethiopia } \\
(n \text { 2962) }\end{array}$} \\
\hline & $\%$ or mean & SD & $\%$ or mean & SD & $\%$ or mean & SD \\
\hline \multicolumn{7}{|l|}{ Dependent variables } \\
\hline \multicolumn{7}{|l|}{ Child undernutrition } \\
\hline Stunting $(\%)$ & $40 \cdot 0$ & - & $16 \cdot 8$ & - & $44 \cdot 4$ & - \\
\hline Underweight (\%) & $38 \cdot 8$ & - & $13 \cdot 2$ & - & $23 \cdot 8$ & - \\
\hline Wasting (\%) & $18 \cdot 4$ & - & $4 \cdot 8$ & - & $6 \cdot 7$ & - \\
\hline $\mathrm{HAZ}$ & $-1 \cdot 65$ & $1 \cdot 37$ & -0.93 & $1 \cdot 19$ & $-1 \cdot 69$ & 1.65 \\
\hline WAZ & $-1 \cdot 68$ & $1 \cdot 14$ & $-0 \cdot 86$ & 1.09 & $-1 \cdot 12$ & $1 \cdot 30$ \\
\hline WHZ & $-1 \cdot 04$ & $1 \cdot 21$ & -0.47 & $1 \cdot 03$ & -0.22 & $1 \cdot 26$ \\
\hline \multicolumn{7}{|l|}{ Child illness during the last 2 weeks (\%) } \\
\hline Diarrhoea & $7 \cdot 5$ & - & $9 \cdot 1$ & - & $15 \cdot 8$ & - \\
\hline Fever & $42 \cdot 8$ & - & $27 \cdot 7$ & - & $26 \cdot 8$ & - \\
\hline Cold/cough & $44 \cdot 2$ & - & $29 \cdot 5$ & - & 31.9 & - \\
\hline Upper ARI (including fever and cold/cough) & $33 \cdot 1$ & - & $15 \cdot 8$ & - & $20 \cdot 0$ & - \\
\hline \multicolumn{7}{|l|}{ Independent variables } \\
\hline \multicolumn{7}{|l|}{ Maternal characteristics } \\
\hline \multicolumn{7}{|l|}{ CMD } \\
\hline High CMD $(\geq 7)$ & $49 \cdot 1$ & - & $31 \cdot 2$ & - & $39 \cdot 7$ & - \\
\hline Low CMD $(<7)$ & $51 \cdot 0$ & - & $68 \cdot 8$ & - & $60 \cdot 9$ & - \\
\hline Age (years) & $26 \cdot 8$ & $6 \cdot 1$ & $29 \cdot 3$ & $5 \cdot 5$ & $29 \cdot 2$ & $6 \cdot 5$ \\
\hline \multicolumn{7}{|l|}{ Education (\%) } \\
\hline No schooling & $26 \cdot 8$ & - & $15 \cdot 7$ & - & $65 \cdot 4$ & - \\
\hline Primary school & $29 \cdot 1$ & - & - & - & $27 \cdot 6$ & - \\
\hline Secondary school & $41 \cdot 7$ & - & $51 \cdot 5$ & - & $7 \cdot 0$ & - \\
\hline High school & $2 \cdot 5$ & - & $20 \cdot 4$ & - & - & - \\
\hline College or higher & - & - & $12 \cdot 4$ & - & - & - \\
\hline Maternal height $(\mathrm{cm})$ & $150 \cdot 8$ & $5 \cdot 5$ & $153 \cdot 0$ & $5 \cdot 3$ & $156 \cdot 5$ & $8 \cdot 6$ \\
\hline Maternal undernutrition $\left(\mathrm{BMI}<18.5 \mathrm{~kg} / \mathrm{m}^{2}\right)(\%)$ & $29 \cdot 6$ & - & $26 \cdot 4$ & - & $24 \cdot 4$ & - \\
\hline \multicolumn{7}{|l|}{ Child's characteristics } \\
\hline Age (months) & $22 \cdot 3$ & $14 \cdot 4$ & $24 \cdot 7$ & $17 \cdot 8$ & $24 \cdot 4$ & $17 \cdot 0$ \\
\hline Low birth weight (\%) & $24 \cdot 0$ & - & $5 \cdot 1$ & - & $31 \cdot 1$ & - \\
\hline \multicolumn{7}{|l|}{ Child gender (\%) } \\
\hline Male & $51 \cdot 6$ & - & $52 \cdot 6$ & - & $51 \cdot 5$ & - \\
\hline Female & $48 \cdot 4$ & - & $47 \cdot 4$ & - & $48 \cdot 5$ & - \\
\hline \multicolumn{7}{|l|}{ Household's characteristics } \\
\hline SES in quintile (\%) & $20 \cdot 0$ & - & $20 \cdot 0$ & - & $20 \cdot 0$ & - \\
\hline \multicolumn{7}{|l|}{ Food security (\%) } \\
\hline Food insecure & $32 \cdot 1$ & - & $38 \cdot 4$ & - & $65 \cdot 5$ & - \\
\hline Food secure & $68 \cdot 0$ & - & $61 \cdot 6$ & - & $34 \cdot 5$ & - \\
\hline Mother is household head (\%) & $9 \cdot 4$ & - & $5 \cdot 9$ & - & $7 \cdot 2$ & - \\
\hline \multicolumn{7}{|l|}{ Hygiene spot score } \\
\hline Child (range: 0-4) & $2 \cdot 9$ & $1 \cdot 6$ & $3 \cdot 2$ & $1 \cdot 12$ & $2 \cdot 4$ & $1 \cdot 6$ \\
\hline Mother (range: 0-4) & $3 \cdot 3$ & $1 \cdot 3$ & $3 \cdot 2$ & $1 \cdot 05$ & $2 \cdot 5$ & $1 \cdot 5$ \\
\hline
\end{tabular}

$\mathrm{HAZ}$, length/height-for-age $Z$-score; WAZ, weight-for-age $Z$-score; WHZ, weight-for-length/height $Z$-score; ARI, acute respiratory infections; CMD, common mental disorders; SES, socio-economic status.

with children of mothers with low CMD, children of mothers with high CMD had a significantly higher proportion of stunting, underweight and wasting in Bangladesh and Vietnam, and a higher proportion of underweight in Ethiopia. Similarly, children of mothers with high CMD also had more illnesses (both diarrhoea and ARI) than their counterparts across the three countries.

\section{Multivariate analyses of the association between maternal common mental disorders and child undernutrition and illness}

The results from logistic regression models on the association between maternal CMD and child undernutrition are presented in Table 2 . The reference category was mothers with low CMD. When adjusting for child, maternal and household factors, mothers with high levels of CMD had significantly higher odds of having a stunted child compared with mothers with low levels of CMD in Bangladesh (adjusted OR $=1 \cdot 21 ; 95 \%$ CI 1·03, 1·41), but not in Vietnam and Ethiopia. Similarly, mothers with high CMD were $1 \cdot 27$ times (95\% CI $1 \cdot 01,1 \cdot 61$ ) more likely to have underweight children than mothers with low CMD in Vietnam. There was no significant association between maternal CMD and wasting in any of the countries when adjusting for confounding factors.

Among other factors, ARI was significantly associated with child undernutrition (stunting, underweight and wasting) in Bangladesh, but not in other two countries. Low birth weight was strongly associated with all three indicators of child undernutrition across the three countries. 

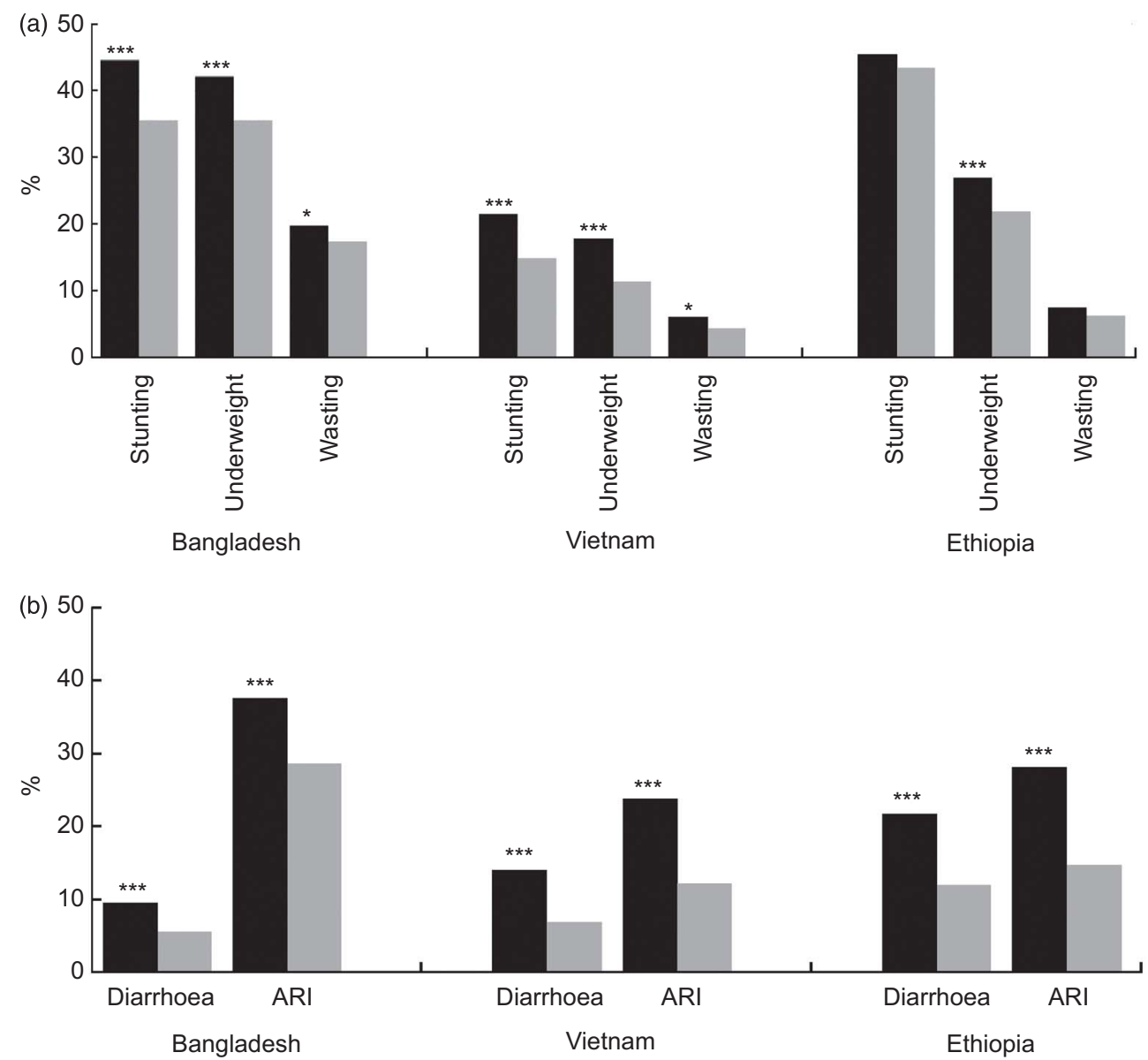

Fig. 1 Bivariate association of maternal common mental disorders (CMD) ( $\square$, high CMD; $\square$, low CMD) with (a) child undernutrition (stunting, underweight and wasting) and (b) child illnesses (diarrhoea and upper acute respiratory infections (ARI) in the past two weeks) in Bangladesh, Vietnam and Ethiopia; baseline data from Alive \& Thrive. ${ }^{\star} P<0 \cdot 05,{ }^{* \star *} P<0 \cdot 001$

Boys were more likely than girls to be wasted in all three countries, and were more likely to be stunted and underweight in Bangladesh and Ethiopia. As expected, lower household SES was associated with higher odds of child undernutrition in all three countries; and household food insecurity was associated with higher odds of stunting in Bangladesh and Ethiopia. Higher maternal education was associated with lower odds of stunting, and taller women had lower odds of having undernourished children in all three countries.

The results of multivariable logistic regression of the association between maternal CMD and child illness symptoms showed that maternal CMD was strongly associated with both child diarrhoea and upper ARI in all three countries (Fig. 1 and Table 3). Compared with children of mothers without CMD, those whose mothers had CMD had $1 \cdot 67$ (95\% CI 1·22, 2·25), 2.11 (95\% CI 1·61, 2.76) and $1 \cdot 83$ (95\% CI $1 \cdot 47,2 \cdot 27)$ times higher odds of experiencing diarrhoea in the two weeks prior to the survey, and 1.41 (95\% CI $1 \cdot 15,1.73), 2.05$ (95\% CI $1.61,2 \cdot 62)$ and $2 \cdot 10$ (95\% CI 1.72, 2.57) times higher odds of having had upper ARI, in Bangladesh, Vietnam and Ethiopia, respectively.

\section{Associations between maternal common mental disorders and maternal and bousebold characteristics, child feeding practices, bygiene and bealth-seeking behaviours}

In an effort to characterize mothers with CMD, we examined the association between CMD and maternal and household characteristics (Table 4). The results showed that maternal CMD was more prevalent among older women, women with lower education level and those suffering from undernutrition (BMI $<18 \cdot 5 \mathrm{~kg} / \mathrm{m}^{2}$ ). Not surprisingly, women living in a food-insecure household or a household of lower SES were much more likely to have high CMD than women from more food-secure or wealthier households. These findings were consistent across all three countries.

When looking at the potential pathways by which maternal CMD might be associated with child health and nutrition, we found that maternal CMD was significantly associated with poorer hygiene practices (proxied by child's cleanliness or mother's cleanliness) and a lower likelihood of having attended prenatal care services (Table 5). These findings were true for all three countries. There was also a pattern of poorer IYCF practices among 
Table 2 Results of multivariate analyses of the association between maternal CMD and child undernutrition in Bangladesh, Vietnam and Ethiopiat; baseline data from Alive \& Thrive

\begin{tabular}{|c|c|c|c|c|c|c|c|c|c|}
\hline & \multicolumn{3}{|c|}{ Stunting } & \multicolumn{3}{|c|}{ Underweight } & \multicolumn{3}{|c|}{ Wasting } \\
\hline & $\begin{array}{l}\text { Bangladesh } \\
\quad(n 4219)\end{array}$ & $\begin{array}{l}\text { Vietnam } \\
(n \text { 3542) }\end{array}$ & $\begin{array}{l}\text { Ethiopia } \\
(n 2578)\end{array}$ & $\begin{array}{l}\text { Bangladesh } \\
\text { (n 4284) }\end{array}$ & $\begin{array}{l}\text { Vietnam } \\
(n \text { 3546) }\end{array}$ & $\begin{array}{l}\text { Ethiopia } \\
(n 2669)\end{array}$ & $\begin{array}{l}\text { Bangladesh } \\
\quad(n \text { 4228) }\end{array}$ & $\begin{array}{l}\text { Vietnam } \\
(n \text { 3543) }\end{array}$ & $\begin{array}{l}\text { Ethiopia } \\
(n 2610)\end{array}$ \\
\hline $\begin{array}{l}\text { High CMD }(\geq 7) \text { (ref. = low CMD }(<7) \text { ) } \\
\text { Child's characteristics }\end{array}$ & $1 \cdot 21^{*}$ & $1 \cdot 09$ & 0.89 & $1 \cdot 09$ & $1 \cdot 27^{*}$ & $1 \cdot 14$ & $1 \cdot 06$ & $1 \cdot 17$ & $1 \cdot 24$ \\
\hline $\begin{array}{l}\text { Age (months) } \\
\text { Child illness }\end{array}$ & $1 \cdot 16^{\star \star *}$ & $1 \cdot 14^{\star \star *}$ & $1 \cdot 12^{\star \star \star}$ & $1 \cdot 10^{* * *}$ & $1 \cdot 03^{\star \star *}$ & $1 \cdot 09^{\star * *}$ & $1 \cdot 04^{*}$ & $1 \cdot 00$ & $0.95^{\star * *}$ \\
\hline $\begin{array}{l}\text { Diarrhoea (ref. }=\text { no) } \\
\text { Upper ARI (ref. = no) }\end{array}$ & $\begin{array}{l}1 \cdot 08 \\
1 \cdot 26^{\star \star}\end{array}$ & $\begin{array}{l}0 \cdot 90 \\
1 \cdot 02\end{array}$ & $\begin{array}{l}1 \cdot 05 \\
1 \cdot 18\end{array}$ & $\begin{array}{l}1 \cdot 15 \\
1 \cdot 21^{\star}\end{array}$ & $\begin{array}{l}0 \cdot 91 \\
1 \cdot 08\end{array}$ & $\begin{array}{l}1 \cdot 22 \\
1 \cdot 18\end{array}$ & $\begin{array}{l}1 \cdot 37^{(*)} \\
1 \cdot 18^{\star}\end{array}$ & $\begin{array}{l}1 \cdot 39 \\
1 \cdot 20\end{array}$ & $\begin{array}{l}1 \cdot 19 \\
1 \cdot 05\end{array}$ \\
\hline Low birth weight (ref. = no) & $1 \cdot 54^{\star \star \star}$ & $3 \cdot 71^{\star \star \star}$ & $1 \cdot 20^{\star}$ & $1 \cdot 95^{\star \star \star}$ & $3 \cdot 96^{\star \star \star}$ & $1 \cdot 41^{\star \star \star}$ & $1 \cdot 71^{\star \star \star}$ & $3 \cdot 61^{\star \star \star}$ & $1 \cdot 50^{\star}$ \\
\hline $\begin{array}{l}\text { Child gender (ref. }=\text { female) } \\
\text { Maternal characteristics }\end{array}$ & $1 \cdot 21^{\star \star \star}$ & $1 \cdot 18$ & $1 \cdot 35^{\star \star \star}$ & $1 \cdot 12^{\star}$ & $0 \cdot 85$ & $1 \cdot 30^{\star \star}$ & $1 \cdot 22^{\star}$ & $1 \cdot 43^{\star}$ & $1 \cdot 45^{\star}$ \\
\hline $\begin{array}{l}\text { Age (years) } \\
\text { Education }\end{array}$ & $1 \cdot 00$ & 0.98 & $1 \cdot 00$ & $1 \cdot 01$ & 0.99 & $1 \cdot 00$ & $1 \cdot 00$ & $1 \cdot 00$ & $1 \cdot 00$ \\
\hline No schooling (ref. in Bangladesh, Ethiopia) & $1 \cdot 00$ & - & $1 \cdot 00$ & $1 \cdot 00$ & - & $1 \cdot 00$ & $1 \cdot 00$ & - & $1 \cdot 00$ \\
\hline Primary school (ref. in Vietnam) & 0.90 & $1 \cdot 00$ & $0 \cdot 78^{*}$ & $1 \cdot 03$ & $1 \cdot 00$ & $0 \cdot 87$ & 0.92 & $1 \cdot 00$ & $0 \cdot 86$ \\
\hline Secondary school & $0 \cdot 82^{(*)}$ & 0.97 & $0 \cdot 65^{\star}$ & 0.93 & $1 \cdot 12$ & $0 \cdot 66^{(\star)}$ & 0.96 & $1 \cdot 17$ & $0 \cdot 71$ \\
\hline High school & $0.52^{(*)}$ & 0.73 & - & $0 \cdot 48^{\star \star}$ & 0.96 & - & 0.61 & $1 \cdot 32$ & - \\
\hline College or higher & - & $0.52^{*}$ & - & - & 0.77 & - & - & $1 \cdot 22$ & - \\
\hline $\begin{array}{l}\text { Maternal height/BMl } \ddagger \\
\text { Household characteristics } \\
\text { SES }\end{array}$ & $0 \cdot 91^{\star \star \star}$ & $0 \cdot 88^{\star \star \star}$ & $0.98^{\star \star \star}$ & $0.93^{\star \star \star}$ & $0 \cdot 91^{\star \star \star}$ & $0.98^{\star \star}$ & $0.98^{(\star)}$ & $0.97^{\star}$ & $1 \cdot 00$ \\
\hline Richest (ref.) & $1 \cdot 00$ & $1 \cdot 00$ & $1 \cdot 00$ & $1 \cdot 00$ & $1 \cdot 00$ & $1 \cdot 00$ & $1 \cdot 00$ & $1 \cdot 00$ & $1 \cdot 00$ \\
\hline Richer & $1 \cdot 34^{*}$ & $1 \cdot 59^{\star}$ & 0.92 & $1 \cdot 30^{\star \star}$ & $1 \cdot 60^{*}$ & $1 \cdot 37^{*}$ & $1 \cdot 13$ & $1 \cdot 58$ & $1 \cdot 59$ \\
\hline Middle & $1 \cdot 72^{\star \star \star}$ & $2 \cdot 05^{\star \star \star}$ & $1 \cdot 06$ & $1 \cdot 44^{\star \star}$ & $1 \cdot 85^{\star \star}$ & $1 \cdot 29$ & 0.98 & $1 \cdot 85^{\star}$ & $1 \cdot 44$ \\
\hline Poorer & $1 \cdot 77^{\star \star \star}$ & $2 \cdot 05^{\star \star \star}$ & $1 \cdot 03$ & $1 \cdot 64^{\star \star \star}$ & $1 \cdot 71^{*}$ & $1 \cdot 37^{\star}$ & $1 \cdot 03$ & $1 \cdot 51$ & $1 \cdot 60^{(*)}$ \\
\hline Poorest & $2 \cdot 36^{\star \star \star}$ & $1 \cdot 72^{*}$ & $1 \cdot 31^{(*)}$ & $2 \cdot 26^{\star \star \star}$ & $1 \cdot 88^{\star \star}$ & $1 \cdot 80^{\star \star \star}$ & $1 \cdot 25^{\star}$ & $2 \cdot 01^{*}$ & $1 \cdot 30$ \\
\hline Food security & & & & & & & & & \\
\hline Security (ref.) & $1 \cdot 00$ & $1 \cdot 00$ & $1 \cdot 00$ & $1 \cdot 00$ & $1 \cdot 00$ & $1 \cdot 00$ & $1 \cdot 00$ & $1 \cdot 00$ & $1 \cdot 00$ \\
\hline Insecurity & $1 \cdot 18$ & $1 \cdot 24^{\star \star}$ & $1 \cdot 22^{*}$ & $1 \cdot 15$ & $1 \cdot 39^{\star}$ & $1 \cdot 15$ & $1 \cdot 13^{(\star)}$ & 0.97 & 0.99 \\
\hline Mother is household head (ref. = no) & $1 \cdot 02$ & 0.97 & $1 \cdot 21$ & $1 \cdot 03$ & $0 \cdot 78$ & $1 \cdot 22$ & $1 \cdot 01$ & $1 \cdot 09$ & 0.90 \\
\hline
\end{tabular}

CMD, common mental disorders; ref., referent category; ARI, acute respiratory infections; SES, socio-economic status.

$\left.{ }^{\star}{ }^{\star}\right) P<0.10,{ }^{\star} P<0.05,{ }^{* \star} P<0.01,{ }^{\star \star \star} P<0.001$.

tResults presented are odds ratios. Models were also adjusted for age squared and cluster effects.

‡Maternal BMI was used for the wasting model.

mothers with high CMD, but differences were statistically significant only for early initiation of breast-feeding in Vietnam and Ethiopia, and for minimum acceptable diet (a composite indicator of appropriate child feeding practices) in Vietnam.

\section{Discussion and conclusions}

The present paper indicates that maternal CMD is a considerable public health problem in Bangladesh, Vietnam and Ethiopia. It also corroborates that maternal CMD is associated with both child undernutrition and common illnesses. After adjusting for potential confounding factors, maternal CMD was associated with $1 \cdot 21$ higher odds of being stunted in Bangladesh and 1.27 higher odds of being underweight in Vietnam. For child illnesses, the associations were even higher and more consistent across countries: children whose mothers had high CMD were more than twice more likely to have upper ARI in Vietnam and Ethiopia (and 1.4 times more likely in Bangladesh); and for diarrhoea, the odds ranged from 1.67 times in Bangladesh to $2 \cdot 11$ times in Vietnam.

To our knowledge, only a few studies, conducted in Chile ${ }^{(39)}$, Nigeria $^{(21)}$, Ethiopia ${ }^{(22)}$ and Pakistan ${ }^{(20)}$, have examined the association between maternal mental health and child illness. Our results showed a strong association between maternal CMD and both diarrhoea and upper ARI in three different countries. These findings suggest that a potential pathway for the relationship between maternal CMD and child undernutrition could be through child illness - as high levels of maternal CMD may hinder a mother's ability to take adequate care of her child, prevent illnesses and seek health care when the child is ill, hence leading to higher illness rates. The illness measurement was based on two-week recall and was similar to the method used in the Demographic and Health Survey. However, the duration and number of episodes of the illnesses were not captured and therefore were not included in the analysis. Other possible mechanisms linking maternal CMD to child growth and child illness include compromised parenting behaviour and non-responsive care-giving practices ${ }^{(40)}$. Our data also showed evidence of poorer hygiene practices, lower use of prenatal care services, and some trends towards poorer IYCF practices among mothers with high CMD. There was also evidence in our data that children's illness symptoms (upper ARI and diarrhoea) were associated with undernutrition, although the associations were statistically significant only in Bangladesh. 
Table 3 Results of multivariate analyses of the association between maternal CMD and child illness in Bangladesh, Vietnam and Ethiopiat; baseline data from Alive \& Thrive

\begin{tabular}{|c|c|c|c|c|c|c|}
\hline & \multicolumn{3}{|c|}{ Diarrhoea } & \multicolumn{3}{|c|}{ Upper ARI } \\
\hline & $\begin{array}{l}\text { Bangladesh } \\
\quad(n \text { 4318 })\end{array}$ & $\begin{array}{l}\text { Vietnam } \\
(n \text { 3557) }\end{array}$ & $\begin{array}{l}\text { Ethiopia } \\
(n \text { 2695) }\end{array}$ & $\begin{array}{l}\text { Bangladesh } \\
(n \text { 4318) }\end{array}$ & $\begin{array}{l}\text { Vietnam } \\
(\text { ( } 3557)\end{array}$ & $\begin{array}{l}\text { Ethiopia } \\
(n \text { 2695) }\end{array}$ \\
\hline $\begin{array}{l}\text { High CMD }(\geq 7) \text { (ref. = low CMD }(<7)) \\
\text { Child's characteristics }\end{array}$ & $1 \cdot 67^{\star \star \star}$ & $2 \cdot 11^{\star \star \star}$ & $1 \cdot 83^{\star \star \star}$ & $1 \cdot 41^{* \star *}$ & $2 \cdot 05^{\star \star \star}$ & $2 \cdot 10^{\star \star \star}$ \\
\hline Age (months) & $1 \cdot 30^{*}$ & $1 \cdot 00$ & $1 \cdot 01$ & 1.09 & $1 \cdot 05^{\star \star \star}$ & $1 \cdot 00$ \\
\hline Low birth weight $($ ref. $=$ no) & $1 \cdot 06^{\star \star}$ & $1 \cdot 06$ & $1 \cdot 01$ & $1 \cdot 01$ & $1 \cdot 18$ & $1 \cdot 13$ \\
\hline $\begin{array}{l}\text { Child gender (ref. = female) } \\
\text { Maternal characteristics }\end{array}$ & $1 \cdot 15^{(*)}$ & $1 \cdot 17$ & $1 \cdot 23^{(*)}$ & $1 \cdot 01$ & 0.95 & 0.92 \\
\hline Age (years) & 0.98 & $0 \cdot 97^{\star \star \star}$ & $1 \cdot 00$ & $0.99^{*}$ & $1 \cdot 00$ & $1 \cdot 00$ \\
\hline \multicolumn{7}{|l|}{ Education } \\
\hline No schooling (ref. in Bangladesh, Ethiopia) & $1 \cdot 00$ & - & $1 \cdot 00$ & $1 \cdot 00$ & - & $1 \cdot 00$ \\
\hline Primary school (ref. in Vietnam) & 0.97 & $1 \cdot 00$ & 1.06 & 0.99 & $1 \cdot 00$ & $1 \cdot 16$ \\
\hline Secondary school & 0.90 & $1 \cdot 28$ & 0.87 & $1 \cdot 01$ & $0 \cdot 87$ & $1 \cdot 27$ \\
\hline High school & $0 \cdot 33^{(*)}$ & 0.98 & - & 0.74 & $0 \cdot 77^{(*)}$ & - \\
\hline College or higher & - & $1 \cdot 23$ & - & - & $0 \cdot 76$ & - \\
\hline \multicolumn{7}{|l|}{$\begin{array}{l}\text { Household characteristics } \\
\text { SFS }\end{array}$} \\
\hline Richest (ref.) & $1 \cdot 00$ & $1 \cdot 00$ & $1 \cdot 00$ & $1 \cdot 00$ & $1 \cdot 00$ & $1 \cdot 00$ \\
\hline Richer & 0.65 & $0 \cdot 82$ & $1 \cdot 22$ & $1 \cdot 08$ & $1 \cdot 11$ & $1 \cdot 08$ \\
\hline Middle & $0 \cdot 76$ & $0 \cdot 86$ & $1 \cdot 11$ & $1 \cdot 17$ & $1 \cdot 09$ & $1 \cdot 86^{\star \star \star}$ \\
\hline Poorer & 0.68 & 0.78 & $1 \cdot 51^{*}$ & $1 \cdot 40^{*}$ & $0 \cdot 88$ & $1 \cdot 62^{* *}$ \\
\hline Poorest & 0.59 & 0.84 & $1 \cdot 65^{\star \star}$ & $1 \cdot 12$ & 0.85 & $1 \cdot 79^{\star * \star}$ \\
\hline \multicolumn{7}{|l|}{ Food security } \\
\hline Security (ref.) & $1 \cdot 00$ & $1 \cdot 00$ & $1 \cdot 00$ & $1 \cdot 00$ & $1 \cdot 00$ & $1 \cdot 00$ \\
\hline Insecurity & $1 \cdot 48^{\star *}$ & $1 \cdot 62^{\star \star *}$ & $1 \cdot 15$ & $1 \cdot 25^{\star *}$ & $1 \cdot 33^{*}$ & $1 \cdot 13$ \\
\hline Mother is household head (ref. $=$ no) & $1 \cdot 01$ & $1 \cdot 12$ & $0.55^{\star}$ & $1 \cdot 24$ & 0.77 & $0 \cdot 81$ \\
\hline \multicolumn{7}{|l|}{ Hygiene spot score } \\
\hline Child's hygiene & 0.95 & 0.91 & 0.96 & $1 \cdot 01$ & $1 \cdot 00$ & 0.95 \\
\hline Mother's hygiene & 0.98 & 0.99 & $0.91^{*}$ & 0.98 & 0.97 & 0.97 \\
\hline
\end{tabular}

CMD, common mental disorders; ref., referent category; ARI, acute respiratory infections; SES, socio-economic status.

${ }^{(*)} P<0.10,{ }^{*} P<0.05,{ }^{* *} P<0.01,{ }^{* * *} P<0.001$.

tResults presented are odds ratios. Models were also adjusted for age squared and cluster effects.

Table 4 Bivariate association of maternal CMD with maternal and household characteristics in Bangladesh, Vietnam and Ethiopia; baseline data from Alive \& Thrive

\begin{tabular}{|c|c|c|c|c|c|c|}
\hline & \multicolumn{2}{|c|}{ Bangladesh } & \multicolumn{2}{|c|}{ Vietnam } & \multicolumn{2}{|c|}{ Ethiopia } \\
\hline & High CMD & Low CMD & High CMD & Low CMD & High CMD & Low CMD \\
\hline \multicolumn{7}{|l|}{ Maternal characteristics } \\
\hline Age (years) & $27 \cdot 52^{\star \star *}$ & $26 \cdot 16$ & $29 \cdot 83^{\star \star \star}$ & $29 \cdot 05$ & $30 \cdot 21^{\star \star \star}$ & $28 \cdot 48$ \\
\hline \multicolumn{7}{|l|}{ Education (\%) } \\
\hline No schooling & $58 \cdot 69^{\star \star \star}$ & $41 \cdot 31$ & $44 \cdot 25^{\star \star \star}$ & $55 \cdot 75$ & $41 \cdot 17^{\star \star \star}$ & $58 \cdot 83$ \\
\hline Primary school & $49 \cdot 61$ & $50 \cdot 39$ & - & - & $37 \cdot 78$ & $62 \cdot 22$ \\
\hline Secondary school & $43 \cdot 61$ & $56 \cdot 39$ & $31 \cdot 04$ & $68 \cdot 96$ & $23 \cdot 79$ & $76 \cdot 21$ \\
\hline High school & $30 \cdot 56$ & $69 \cdot 44$ & $27 \cdot 66$ & $72 \cdot 34$ & - & - \\
\hline College or higher & - & - & $21 \cdot 57$ & $78 \cdot 43$ & - & - \\
\hline \multicolumn{7}{|l|}{ BMI (\%) } \\
\hline $\mathrm{BMI}<18.5 \mathrm{~kg} / \mathrm{m}^{2}$ & $55 \cdot 02^{\star \star \star}$ & $44 \cdot 98$ & $36 \cdot 39^{\star \star \star}$ & $70 \cdot 67$ & $43 \cdot 75^{\star \star}$ & $56 \cdot 25$ \\
\hline $\mathrm{BMI} \geq 18.5 \mathrm{~kg} / / \mathrm{m}^{2}$ & $46 \cdot 60$ & $53 \cdot 40$ & $29 \cdot 33$ & $63 \cdot 61$ & $37 \cdot 37$ & $62 \cdot 63$ \\
\hline \multicolumn{7}{|l|}{ Household characteristics } \\
\hline \multicolumn{7}{|l|}{ SES (\%) } \\
\hline Poorest & $61 \cdot 25^{\star \star \star}$ & $38 \cdot 57$ & $41 \cdot 77^{\star \star \star}$ & $58 \cdot 23$ & $50 \cdot 42^{\star \star \star}$ & $49 \cdot 58$ \\
\hline Poorer & $53 \cdot 64$ & $46 \cdot 36$ & $33 \cdot 54$ & $66 \cdot 46$ & $41 \cdot 65$ & $58 \cdot 35$ \\
\hline Middle & $47 \cdot 95$ & $52 \cdot 05$ & $33 \cdot 29$ & $66 \cdot 71$ & 33.95 & $66 \cdot 05$ \\
\hline Richer & $43 \cdot 86$ & $56 \cdot 14$ & $25 \cdot 19$ & $74 \cdot 81$ & $33 \cdot 78$ & $66 \cdot 22$ \\
\hline Richest & $38 \cdot 52$ & $61 \cdot 48$ & $22 \cdot 32$ & $77 \cdot 68$ & $35 \cdot 47$ & $64 \cdot 53$ \\
\hline \multicolumn{7}{|l|}{ Food security (\%) } \\
\hline Food insecure & $65 \cdot 25^{\star \star \star}$ & $34 \cdot 75$ & $50 \cdot 00^{\star \star *}$ & $50 \cdot 00$ & $46 \cdot 11^{\star \star \star}$ & $53 \cdot 89$ \\
\hline Food secure & $41 \cdot 40$ & $58 \cdot 60$ & $19 \cdot 54$ & $80 \cdot 46$ & $25 \cdot 78$ & $74 \cdot 22$ \\
\hline
\end{tabular}

CMD, common mental disorders; SES, socio-economic status.

${ }^{\star *} P<0.01,{ }^{\star * \star} P<0.001$. 
Table 5 Bivariate association of maternal CMD with child feeding practices, hygiene and health-seeking behaviours in Bangladesh, Vietnam and Ethiopia; baseline data from Alive \& Thrive

\begin{tabular}{|c|c|c|c|c|c|c|}
\hline & \multicolumn{2}{|c|}{ Bangladesh } & \multicolumn{2}{|c|}{ Vietnam } & \multicolumn{2}{|c|}{ Ethiopia } \\
\hline & High CMD & Low CMD & High CMD & Low CMD & High CMD & Low CMD \\
\hline & $\%$ & $\%$ & $\%$ & $\%$ & $\%$ & $\%$ \\
\hline \multicolumn{7}{|l|}{ Child feeding practices } \\
\hline Early initiation of breast-feeding & $64 \cdot 86$ & $63 \cdot 02$ & $53 \cdot 93^{\star \star}$ & $60 \cdot 25$ & $62 \cdot 86^{*}$ & $69 \cdot 00$ \\
\hline Exclusive breast-feeding & $47 \cdot 61$ & $51 \cdot 67$ & $17 \cdot 87$ & $18 \cdot 51$ & $68 \cdot 98$ & $74 \cdot 36$ \\
\hline Minimum dietary diversity ( $\geq 4$ food groups) & \multirow{2}{*}{$\begin{array}{l}30 \cdot 15 \\
37 \cdot 69\end{array}$} & $31 \cdot 92$ & 73.96 & $75 \cdot 13$ & $5 \cdot 65$ & $6 \cdot 68$ \\
\hline Minimum meal frequencyt & & $41 \cdot 53$ & $77 \cdot 51$ & $82 \cdot 41$ & $42 \cdot 86$ & $47 \cdot 31$ \\
\hline Minimum acceptable dietł & $14 \cdot 07$ & $15 \cdot 47$ & $49 \cdot 41^{\star \star *}$ & $60 \cdot 32$ & $3 \cdot 87$ & $5 \cdot 01$ \\
\hline Consumption of Fe-rich foods $\S$ & $34 \cdot 67$ & $37 \cdot 62$ & $83 \cdot 43$ & $86 \cdot 51$ & $1 \cdot 79$ & $2 \cdot 23$ \\
\hline Child illness & & & & & & \\
\hline Fever symptoms & $47 \cdot 41^{* \star *}$ & $38 \cdot 31$ & $37 \cdot 22^{\star \star *}$ & $23 \cdot 42$ & $36 \cdot 30^{\star \star \star}$ & $20 \cdot 50$ \\
\hline Cough/cold symptoms & $47 \cdot 87^{\star \star \star}$ & $40 \cdot 68$ & $40 \cdot 81^{\star \star *}$ & $24 \cdot 40$ & $39 \cdot 33^{\star \star \star}$ & $26 \cdot 87$ \\
\hline Fast breathing symptoms & $12 \cdot 14^{\star \star \star}$ & $5 \cdot 89$ & $8 \cdot 55^{\star \star \star}$ & $2 \cdot 54$ & $14 \cdot 43^{\star \star \star}$ & $6 \cdot 15$ \\
\hline Diarrhoea symptoms & $9 \cdot 55^{\star \star \star}$ & $5 \cdot 58$ & $14 \cdot 06^{\star \star \star}$ & $6 \cdot 89$ & $21 \cdot 78^{\star * \star}$ & $12 \cdot 02$ \\
\hline Health-seeking behaviour & & & & & & \\
\hline Consultation health professional during last pregnancy & $75 \cdot 63^{\star \star}$ & $79 \cdot 08$ & $50 \cdot 72^{\star \star *}$ & $56 \cdot 27$ & $62 \cdot 83^{*}$ & $66 \cdot 76$ \\
\hline Mother takes Fe supplements & $60 \cdot 79^{\star *}$ & $65 \cdot 19$ & $86 \cdot 64$ & $93 \cdot 40$ & $27 \cdot 23$ & $29 \cdot 26$ \\
\hline & Mean SD & Mean SD & Mean & Mean SD & Mean SD & Mean SD \\
\hline Hygiene spot score & & & & & & \\
\hline Child's cleanliness & $2 \cdot 73^{\star \star *} 1.67$ & $3.03 \quad 1.58$ & $3 \cdot 01^{\star * *} 1 \cdot 21$ & $3.29 \quad 1.06$ & $2 \cdot 17^{\star \star *} 1 \cdot 62$ & $2.53 \quad 1.54$ \\
\hline Mother's cleanliness & $3 \cdot 23^{\star \star *} 1 \cdot 32$ & $3.43 \quad 1.24$ & $3 \cdot 07^{\star \star *} 1 \cdot 12$ & $3.26 \quad 1.01$ & $2 \cdot 26^{\star * *} 1 \cdot 48$ & $2.59 \quad 1.44$ \\
\hline
\end{tabular}

CMD, common mental disorders.

${ }^{\star} P<0.05,{ }^{\star \star} P<0.01,{ }^{\star * \star} P<0.001$.

tMinimum meal frequency is defined as 2 times/d for breast-fed infants aged 6-8 months; 3 times/d for breast-fed children aged 9-23.9 months; 4 times/d for non-breast-fed children aged 6-23.9 months. 'Meals' include both meals and snacks and frequency is based on mother's report.

$\ddagger$ Acceptable diet is defined as at least the minimum dietary diversity and the minimum meal frequency during the previous day.

SFe-rich or Fe-fortified foods include flesh foods, commercially fortified foods especially designed for infants and young children that contain Fe, or foods fortified in the home with a micronutrient powder containing Fe.

The lack of an association between maternal CMD and child undernutrition in Ethiopia is consistent with recent findings from a prospective cohort study in Ethiopia. The latter study showed that maternal CMD was associated with child underweight at 12 months in a bivariate analysis, but the association did not remain after adjusting for maternal characteristics or household characteristics ${ }^{(17)}$.

The variability in findings among the three countries, especially regarding the association between maternal CMD and child undernutrition, may be explained by socio-cultural differences in care and feeding practices, differences in maternal resources such as education, knowledge or time, or in household food insecurity and wealth ${ }^{(18)}$. In our data, the two variables that were most different among the three countries were maternal education (with $65.4 \%$ of women in Ethiopia having no schooling compared with $26.8 \%$ of women in Bangladesh and $15.7 \%$ of women in Vietnam) and household food insecurity (the prevalence of food insecurity was twice as high in Ethiopia as it was in Bangladesh and Vietnam). We examined whether the association between maternal CMD and child nutrition outcomes in Ethiopia differed by maternal education, household SES or food insecurity, but we did not find evidence of such interactions (results not shown). It is possible, therefore, that the variability in the associations across countries could be attributable to broader socio-cultural issues, including potential differences in access to social support mechanisms or social networks within communities for women with high CMD.

The high prevalence of maternal CMD among women in the three countries and the associated risk of high CMD for child undernutrition and child illness suggest that interventions to address maternal mental well-being, and the factors that influence mental well-being, could make important contributions to improving the health and nutrition of children. Several environmental and povertyrelated factors were associated with CMD in our analyses (lower education, living in a food-insecure or a lower-SES household), which suggests that attempts to relieve some of these constraints (e.g. through poverty reduction, social protection, women's empowerment programmes) may be necessary to help improve maternal mental well-being. In the context of behaviour change interventions which aim at reducing undernutrition and death in children by improving IYCF practices, CMD might be an important factor that prevents mothers either from participating in the programme or from adopting recommended practices ${ }^{(6,41)}$. Further, programme interventions focused on the creation of women's groups and health committees to discuss maternal and child health problems and formulate approaches to deal with them based on methods learned within these group settings have also shown to be successful in improving maternal mental health and breast-feeding practices, indicating that 
interventions centred around improving maternal CMD can be an important aspect to consider ${ }^{(42)}$. It would therefore be important to examine the role of maternal mental well-being in relation to participation in public health programmes and adoption of public health recommendations that require behaviour change.

The strengths of the present study include the large samples of mother-child dyads in the three countries and the use of the same questionnaire and survey methodology, which allowed for a valid comparison across countries. The instrument used to capture maternal CMD was validated for use in developing countries ${ }^{(30)}$ and was locally adapted by taking cultural and social factors into consideration. Finally, the availability of data on a wide range of child, maternal and household factors in the surveys allowed us to control for a range of potentially confounding factors and isolate the association between maternal CMD and child undernutrition and illness.

Two limitations of the study merit further discussion. First, data were collected based on maternal recall of their emotional distress in the last four weeks (for CMD) and of their children's symptoms of illness in the two weeks prior to the interview. Maternal recall has its limitations and can result in either under- or over-reporting of information. We do not have evidence, however, to suggest that maternal CMD could adversely affect recall and assume, therefore, that recall biases for CMD and illness are randomly distributed across the sample. The cut-off point used to categorize the level of high and low maternal CMD was supported by one validation study ${ }^{(32)}$ and it is possible that the cut-off itself is not uniformly applicable across countries. However, analyses with the continuous variables for CMD yielded similar results. Second, the cross-sectional nature of the data used for the present analysis did not allow us to establish the causal relationship of maternal CMD with child undernutrition and illness. The potential of reverse causality cannot be ruled out as children's poor growth or illness may cause maternal stress or mental distress, which in turn may impede the ability of mothers to take adequate care of their children and lead to compromised growth and increased prevalence of infections ${ }^{(5)}$. Several studies support this hypothesis. Preterm birth and failure to thrive among children have been found to be associated with postnatal depression ${ }^{(18,43,44)}$. Additionally, there is evidence from intervention trials showing that interventions targeted to the child, through early child stimulation activities, have positive effects on reducing maternal depression ${ }^{(45)}$. This further suggests reverse causality of the relationship between CMD and child undernutrition.

The results from the present study contribute to the growing evidence of the potential negative effects of maternal mental health on child undernutrition and illness. The findings underscore the importance of identifying ways to prevent, detect and address maternal mental health in the context of programmes aimed at improving child health and nutrition in these countries and in similar settings elsewhere.

\section{Acknowledgements}

Sources of funding: The study was supported by the Bill \& Melinda Gates Foundation through Alive \& Thrive (A\&T), managed by FHI360. Conflicts of interest: There is no conflict of interest. Authors' contributions: P.H.N. participated in the concept and design, coordinated data collection in Vietnam, performed statistical analysis of the data, and drafted and revised the manuscript. K.K.S. coordinated data collection in Bangladesh, provided comments for the analyses, contributed to the introduction and discussion, and edited the paper. D.A. coordinated data collection in Ethiopia, provided comments for the analyses, and contributed to the introduction and discussion. P.M. participated in the overall design of the baseline survey and provided comments/inputs for the analyses and manuscript. S.M. participated in the literature review and provided background for the topics. L.T.M. assisted in the analyses and prepared tables/figures. R.R. participated in the overall design of the baseline survey. M.T.R. participated in the overall design of the baseline survey, provided comments/inputs for the analyses and revised the manuscript. Acknowledgements: The authors are grateful to Ali Subandoro for research assistance and to Edward Frongillo for statistical advice.

\section{References}

1. World Health Organization (2004) The Importance of Caregiver-Child Interactions for the Survival and Healthy Development of Young Children: A Review. Geneva: WHO.

2. Bhutta ZA, Ahmed T, Black RE et al. (2008) What works? Interventions for maternal and child undernutrition and survival. Lancet 371, 417-440.

3. Engle PL \& Lhotska L (1999) The role of care in programmatic actions for nutrition: designing programmes involving care. Food Nutr Bull 20, 121-135.

4. UNICEF (1998) The State of the World's Children 1998. New York: Oxford University Press.

5. Stewart RC (2007) Maternal depression and infant growth: a review of recent evidence. Matern Child Nutr 3, 94-107.

6. Rahman A, Patel V, Maselko J et al. (2008) The neglected ' $m$ ' in MCH programmes - why mental health of mothers is important for child nutrition. Trop Med Int Health 13, 579-583.

7. Walker SP, Wachs TD, Gardner JM et al. (2007) Child development: risk factors for adverse outcomes in developing countries. Lancet 369, 145-157.

8. Patel P, Wheatcroft R, Park RJ et al. (2002) The children of mothers with eating disorders. Clin Child Fam Psychol Rev 5, 1-19.

9. Patel V, DeSouza N \& Rodrigues M (2003) Postnatal depression and infant growth and development in low income countries: a cohort study from Goa, India. Arch Dis Child 88, 34-37.

10. Black MM, Baqui AH, Zaman K et al. (2009) Maternal depressive symptoms and infant growth in rural Bangladesh. Am J Clin Nutr 89, issue 3, 951S-957S. 
11. Rahman A, Lovel H, Bunn J et al. (2004) Mothers' mental health and infant growth: a case-control study from Rawalpindi, Pakistan. Child Care Health Dev 30, 21-27.

12. Harpham T, Huttly S, De Silva MJ et al. (2005) Maternal mental health and child nutritional status in four developing countries. J Epidemiol Community Health 59, 1060-1064.

13. Surkan PJ, Kawachi I, Ryan LM et al. (2008) Maternal depressive symptoms, parenting self-efficacy, and child growth. Am J Public Health 98, 125-132.

14. Santos DS, Santos DN, de Cassia Ribeiro Silva R et al. (2010) Maternal common mental disorders and malnutrition in children: a case-control study. Soc Psychiatry Psychiatr Epidemiol 46, 543-548.

15. Stewart RC, Umar E, Kauye F et al. (2008) Maternal common mental disorder and infant growth - a crosssectional study from Malawi. Matern Child Nutr 4, 209-219.

16. Tomlinson M, Cooper PJ, Stein A et al. (2006) Post-partum depression and infant growth in a South African peri-urban settlement. Child Care Health Dev 32, 81-86.

17. Medhin G, Hanlon C, Dewey M et al. (2010) The effect of maternal common mental disorders on infant undernutrition in Butajira, Ethiopia: the P-MaMiE study. BMC Psychiatry 10, 32 .

18. Surkan PJ, Kennedy CE, Hurley KM et al. (2011) Maternal depression and early childhood growth in developing countries: systematic review and meta-analysis. Bull World Health Organ 89, 608-615.

19. Rahman A, Iqbal Z, Bunn J et al. (2004) Impact of maternal depression on infant nutritional status and illness: a cohort study. Arch Gen Psychiatry 61, 946-952.

20. Rahman A, Bunn J, Lovel H et al. (2007) Maternal depression increases infant risk of diarrhoeal illness: a cohort study. Arch Dis Child 92, 24-28.

21. Adewuya AO, Ola BO, Aloba OO et al. (2008) Impact of postnatal depression on infants' growth in Nigeria. J Affect Disord 108, 191-193.

22. Ross J, Hanlon C, Medhin G et al. (2011) Perinatal mental distress and infant morbidity in Ethiopia: a cohort study. Arch Dis Child Fetal Neonatal Ed 96, F59-F64.

23. Nguyen PH, Manohar S, Mai LT et al. (2010) Viet Nam Baseline Survey Report. Alive and Thrive Project. Washington, DC: International Food Policy Research Institute.

24. Saha KK, Bamezai A, Khaled A et al. (2010) Bangladesh Baseline Survey Report. Alive and Thrive Project. Washington, DC: International Food Policy Research Institute.

25. Ali D, Tedla M, Subandoro A et al. (2010) Ethiopia Baseline Survey Report. Alive and Thrive Project. Washington, DC: International Food Policy Research Institute.

26. Cogill B (2003) Anthropometric Indicators Measurement Guide. Food and Nutrition Technical Assistance Project. Washington, DC: Academy for Educational Development.

27. World Health Organization (2010) The WHO Child Growth Standards. http://www.who.int/childgrowth/standards/en/ (accessed July 2012).

28. UNICEF/World Health Organization (2009) Diarrhoea: Why Children are Still Dying and What Can be Done. Geneva: WHO.

29. World Health Organization (2007) Infection Prevention and Control of Epidemic- and Pandemic-Prone Acute Respiratory Diseases in Health Care. WHO Interim Guidelines. Geneva: WHO.
30. World Health Organization (1994) A User's Guide to Self-Reporting Questionnaires. Geneva: Division of Mental Health, WHO.

31. Hanlon C, Medhin G, Alem A et al. (2008) Detecting perinatal common mental disorders in Ethiopia: validation of the self-reporting questionnaire and Edinburgh Postnatal Depression Scale. J Affect Disord 108, 251-262.

32. Giang KB, Allebeck P, Kullgren G et al. (2006) The Vietnamese version of the Self Reporting Questionnaire 20 (SRQ-20) in detecting mental disorders in rural Vietnam: a validation study. Int J Soc Psychiatry 52, 175-184.

33. Vyas S \& Kumaranayake L (2006) Constructing socioeconomic status indices: how to use principal components analysis. Health Policy Plan 21, 459-468.

34. Gwatkin D, Rutstein S, Johnson K et al. (2007) Socioeconomic differences in health, nutrition, and population within developing countries: an overview. Niger J Clin Pract 10, 272-282.

35. Coates J, Swindale A \& Bilinsky P (2007) Housebold Food Insecurity Access Scale (HFIAS) for Measurement of Housebold Food Access: Indicator Guide (v. 3). Washington, DC: Food and Nutrition Technical Assistance Project, Academy for Educational Development.

36. Daelmans B, Dewey K \& Arimond M (2009) New and updated indicators for assessing infant and young child feeding. Food Nutr Bull 30, 2 Suppl., S256-S262.

37. World Health Organization (2008) Indicators for Assessing Infant and Young Child Feeding Practices: Conclusions of a consensus meeting beld 6-8 November 2007 in Washington, DC, USA. Geneva: WHO.

38. Ruel MT \& Arimond M (2002) Spot-check observational method for assessing hygiene practices: review of experience and implications for programmes. J Health Popul Nutr 20, 65-76.

39. Humphreys D, Araya M, Cruchet S et al. (1996) Maternal neurotic symptoms and infants' risk of developing persistent diarrhoea. Rev Saude Publica 30, 213-217.

40. Rahman A, Harrington R \& Bunn J (2002) Can maternal depression increase infant risk of illness and growth impairment in developing countries? Child Care Health Dev 28, 51-56.

41. Field T (2010) Postpartum depression effects on early interactions, parenting, and safety practices: a review. Infant Behav Dev 33, 1-6.

42. Tripathy P, Nair N, Barnett S et al. (2010) Effect of a participatory intervention with women's groups on birth outcomes and maternal depression in Jharkhand and Orissa, India: a cluster-randomised controlled trial. Lancet 375, 1182-1192.

43. Vigod SN, Villegas L, Dennis CL et al. (2010) Prevalence and risk factors for postpartum depression among women with preterm and low-birth-weight infants: a systematic review. BJOG 117, 540-550.

44. Drewett R, Blair P, Emmett P et al. (2004) Failure to thrive in the term and preterm infants of mothers depressed in the postnatal period: a population-based birth cohort study. J Child Psychol Psychiatry 45, 359-366.

45. Baker-Henningham H, Powell C, Walker S et al. (2005) The effect of early stimulation on maternal depression: a cluster randomised controlled trial. Arch Dis Child $\mathbf{9 0}$, 1230-1234. 